\title{
The Metabolic Syndrome: Comparison of Newly Proposed IDF, Modified ATP III and WHO Criteria and their Agreements
}

\author{
AKM Mainuddin, ${ }^{1}$ KN Choudhury, ${ }^{2}$ KR Ahmed, ${ }^{3}$ S Akter, ${ }^{1}$ N Islam, ${ }^{2}$ JHB Masud, ${ }^{3}$ \\ ${ }^{1}$ University of Dhaka, ${ }^{2}$ National Centre for Control of Rheumatic Fever and Heart Disease, Dhaka, \\ ${ }^{3}$ Bangladesh University of Health Sciences.
}

Key words:

Metabolic

Syndrome, IDF, ATP III, WHO, Agreement.

\begin{abstract}
:
Background: Metabolic syndrome (MS) results from clustering of cardiovascular risk factors occurring in association with insulin resistance and obesity. With the increasing prevalence of obesity worldwide, MS is of keen interest in research. The disorder is defined in various ways, but one consolidated definition is needed to make studies comparable worldwide. The study was to determine the risk factors of metabolic syndrome in Bangladesh and comparison of newly proposed definition of International Diabetes Federation (IDF), modified National Cholesterol Education Program Adult Treatment Panel III (NCEP ATP III) and the World Health Organization (WHO) criteria and their agreements.
\end{abstract}

Materials and Methods: This was a cross sectional hospital based study. We randomly selected 229 participants. After obtaining informed written consent data collectors collected data by interview, clinical examination, anthropometric measurement and investigations. We calculated independent sample t-test means between to distinguish which risk factors were present in participants with and without MS, using SPSS 17 .

Results: The percentage of risk factors of MS among subjects according to different criteria was $72 \%$ of Modified ATP-III, 69\% of IDF and 39\% of WHO definition .In Modified NCEP ATP III when did independent sample t-test mean of BMI, waist circumference, systolic blood pressure, diastolic blood pressure, fasting blood glucose, high density lipoprotein and triglyceride were present statistically significant difference between without MS and with MS ( $p<0.05)$. According to WHO criteria BMI, waist circumference, fasting blood glucose were statistically significant $(p<0.05)$ and similarly fasting blood glucose \& triglyceride were statistically significant difference between without MS and with $M S(p<0.05)$ according to IDF criteria.ATP III and WHO criteria showed good agreement (k 0.56) compared to ATP III with IDF ( $k$ 0.31) and WHO with IDF (k 0.11) criteria.

Conclusion: Metabolic syndrome is highly prevalent in Bangladesh. We detected the highest proportion of participants with MS using the ATP III definition, which emphasizes the predominant focus on the modified waist circumference for Asian participants. However, MS prevalence following WHO criteria in those with impaired glucose regulation is comparable with ATP III definition. Follow up study needed to examine the significance of MS following all definitions for the assessment of risk for diabetes and or cardiovascular disease.

(Cardiovasc. j. 2013; 6(1): 17-22)

\section{Introduction:}

Metabolic syndrome (MS) is characterized by multiple risk factors, including abnormal fat distribution, dyslipidemia, hypertension and hyperglycemia in relation to insulin resistance and obesity and persons with MS are considered to have high risk of cardiovascular diseases (CVD) and diabetes mellitus (DM). ${ }^{1,2}$ Diabetes and cardiovascular diseases often appear as the two sides of a coin: on one side diabetes mellitus has been rated as an equivalent of coronary heart disease and conversely many patients with established coronary heart disease suffer from diabetes or pre-states. ${ }^{3}$ Longitudinal clinical and epidemiological studies consistently demonstrated that certain risk factors are important as causes of the mass occurrence of CVD in populations and also serve as contributing factors to increased risk at individual level. These risk factors linked to unhealthy life styles such as unhealthy eating habits, physical inactivity, overweight/abdominal obesity, and smoking. This 
implies that, if one component is identified a systematic search for the others is indicated; together with an active approach to managing all of these risk factors. ${ }^{4,5}$

Metabolic syndrome is defined in various ways, but in the near future a new definition will be applicable worldwide. MS increased the risk of atherosclerotic cardiovascular disease (ASCVD) and diabetes. ${ }^{6} \mathrm{MS}$ patients are at a higher risk for heart failure. The risk for ASCVD associated with MB is greater than the sum of its risk factors as the risk factors are multiplicative. The fundamental management approach for MS patients includes weight reduction and increased physical activity; however, drug treatment could be appropriate for diabetes and cardiovascular risk reduction. ${ }^{6}$

The study was to determine the risk factors of metabolic syndrome in Bangladesh and comparison of newly proposed definition of International Diabetes Federation (IDF), modified ATP III and the World Health Organization (WHO) criteria and their agreements.

\section{Defining the metabolic syndrome:}

Several definition of metabolic syndrome are existing, including the most accepted WHO (1999) and National Cholesterol Education Program Adult Treatment Panel III (2001) ${ }^{4}$ definitions (See Table 1). Obesity, insulin resistance/hyperglycemia and dyslipidemias are common components in all definitions.

In retrospect, it is apparent that the WHO definition was better suited as a research tool whereas the NCEP: ATP-III definition was more useful for clinical practice. ${ }^{5}$ Clinicians prefer simple tools to assess patients and improve their management and it is generally agreed that the NCEP: ATP-III definition is simpler for practice.

A problem with the WHO and the NCEP: ATPIII has been their applicability to different ethnic groups, especially as relates to obesity cutoffs. ${ }^{7}$ The International Diabetes Federation (IDF) felt there was a strong need for one practical definition that would be useful in any country for the identification of people at high risk for CVD and diabetes. ${ }^{8}$

\section{Methods:}

\section{Subjects:}

We selected participants $(\mathrm{n}=229)$ for this cross sectional study, from National Center for Control of Rheumatic Fever and Heart Diseases, in urban Dhaka, Bangladesh. These patients sought a thorough health check up including blood pressure assessment between January to June 2012. All of the subjects were residents of the surrounding areas and aged 30-60 years having risk factors of metabolic syndrome. Patients with features of any cardiac or renal complication and major medical problem were excluded. After obtaining informed consent data collectors completed data sheet by interview, clinical examination, anthropometric measurement and investigations.

\section{Blood Examination:}

Twelve-hour fasting blood in the morning had drawn from all of the subjects. Blood was obtained and biochemical measurements were conducted in a routine manner in the laboratory of National center for control of rheumatic fever and heart diseases. The serum triglycerides and HDL- cholesterol concentrations and fasting serum glucose concentration were measured in enzymatic methods.

\section{Other Measurements:}

Age, sex, weight and height were recorded. Body mass index was calculated by weight (kg) divided by the square of height $\left(\mathrm{m}^{2}\right)$. Abdominal obesity was evaluated with measuring abdominal circumference at the level of the umbilicus by trained nurses. Systolic and diastolic blood pressures were measured using a sphygmomanometer, with a subject sitting on a chair after at least a five-minute rest.

\section{Statistical Analyses:}

We categorized the participants using the three definitions in Table 1. Statistical analyses were performed using SPSS for Windows version 17 software. $t$ tests were used for continuous variable and chi square test for proportions to detect syndromes between MS and non MS patients. Kappa $(\hat{e})$ statistics was used for finding the agreement among the three definitions. $P$-value $<0.05$ was considered significant level. 
Table-I

Criteria for diagnosis of metabolic syndrome $e^{4,7,8}$

\begin{tabular}{|c|c|c|c|}
\hline Components & NCEP/ ATPIII & World Health Organization & $\begin{array}{l}\text { International Diabetes } \\
\text { Foundation }\end{array}$ \\
\hline & $\begin{array}{l}\text { Three of the following } \\
\text { five components }\end{array}$ & $\begin{array}{l}\text { Presence of diabetes mellitus, } \\
\text { impaired glucose tolerance, } \\
\text { impaired fasting glucose or } \\
\text { insulin resistance plus two of } \\
\text { the following five components }\end{array}$ & $\begin{array}{l}\text { Central obesity (as defined } \\
\text { by waist circumference) plus } \\
\text { any two of the following }\end{array}$ \\
\hline Central Obesity & $\begin{array}{l}\text { 1. Waist circumference } \\
>90 \mathrm{~cm} \text { in men and }>80 \\
\mathrm{~cm} \text { in women for } \\
\text { Asians }\end{array}$ & $\begin{array}{l}\text { 1. Waist to hip ratio of }>0.9 \\
\text { (men) or }>0.85 \text { (women) and or } \\
\text { body mass index }>30 \mathrm{~kg} / \mathrm{m}^{2}\end{array}$ & $\begin{array}{l}\text { Waist circumference } 90 \mathrm{~cm} \\
\text { for men and e' } 80 \mathrm{~cm} \text { for } \\
\text { women (Ethnicity specific } \\
\text { for South Asians) }\end{array}$ \\
\hline Dyslipidemia & $\begin{array}{l}\text { 2. Triglycerides } 150 \\
\mathrm{mg} / \mathrm{dl} \\
\text { 3. Low HDL } \\
\text { cholesterol: }<40 \mathrm{mg} / \mathrm{dl} \\
\text { in men and }<50 \mathrm{mg} / \mathrm{dl} \\
\text { in women }\end{array}$ & $\begin{array}{l}\text { 2. Triglycerides } 150 \mathrm{mg} / \mathrm{dl} \text { and } \\
\text { /or HDL cholesterol }<35 \mathrm{mg} / \mathrm{dl} \\
\text { (men) and }<39 \mathrm{mg} / \mathrm{dl} \text { (women) }\end{array}$ & $\begin{array}{l}\text { 1. Triglycerides } 150 \mathrm{mg} / \mathrm{dl} \\
\text { or specific treatment for this } \\
\text { lipid abnormality } \\
\text { 2. Reduced HDL-cholesterol } \\
<40 \mathrm{mg} / \mathrm{dL} \text { (men), }<50 \mathrm{mg} / \\
\mathrm{dL} \text { (women) or specific } \\
\text { treatment for this lipid } \\
\text { abnormality }\end{array}$ \\
\hline $\begin{array}{l}\text { High blood } \\
\text { pressure }\end{array}$ & $\begin{array}{l}\text { 4. Blood pressure } \\
130 / 85 \mathrm{~mm} \mathrm{Hg}\end{array}$ & $\begin{array}{l}\text { 3. Blood Pressure 140/90 mm } \\
\mathrm{Hg}\end{array}$ & $\begin{array}{l}\text { 3. Blood pressure } 130 / 85 \\
\text { mm Hg or treatment of } \\
\text { previously diagnosed } \\
\text { hypertension. }\end{array}$ \\
\hline $\begin{array}{l}\text { High plasma } \\
\text { glucose }\end{array}$ & $\begin{array}{l}\text { 5. Fasting glucose : } \\
6.1 \mathrm{mmol} / \mathrm{L}\end{array}$ & $\begin{array}{l}\text { 4. Microalbuminuria: urinary } \\
\text { albumin excretion rate } 20 \mu \\
\mathrm{g} / \mathrm{min} \text { or albumin creatinine ratio } \\
30 \mathrm{mg} / \mathrm{g}\end{array}$ & $\begin{array}{l}\text { 4. Fasting plasma glucose } \\
5.6 \mathrm{mmol} / \mathrm{L} \text { or previously } \\
\text { diagnosed type } 2 \text { diabetes. }\end{array}$ \\
\hline
\end{tabular}

\section{Results:}

The percentage of risk factors of MS among subjects according to different criteria was $72 \%$ of the Modified NCEP ATP-III, 69\% of IDF (See Figure-1) and 39\% of WHO definition (See Table$2)$. Women showed higher MS occurrence according to all three classifications.

\section{Table-II}

Presence of risk factors of metabolic syndrome (MS) among subjects according to different criteria $(n=229)$ in a hospital

\begin{tabular}{lccc}
\hline Criteria & $\begin{array}{c}\text { Male } \\
\mathrm{n}(\%)\end{array}$ & $\begin{array}{c}\text { Female } \\
\mathrm{n}(\%)\end{array}$ & $\begin{array}{c}\text { Total } \\
\mathrm{n}(\%)\end{array}$ \\
\hline Modified NCEP ATPIII & $66(66)$ & $99(76.7)$ & $165(72.1)$ \\
WHO & $36(36)$ & $53(41.1)$ & $89(38.9)$ \\
IDF & $50(50)$ & $107(82.9)$ & $157(68.6)$ \\
\hline
\end{tabular}

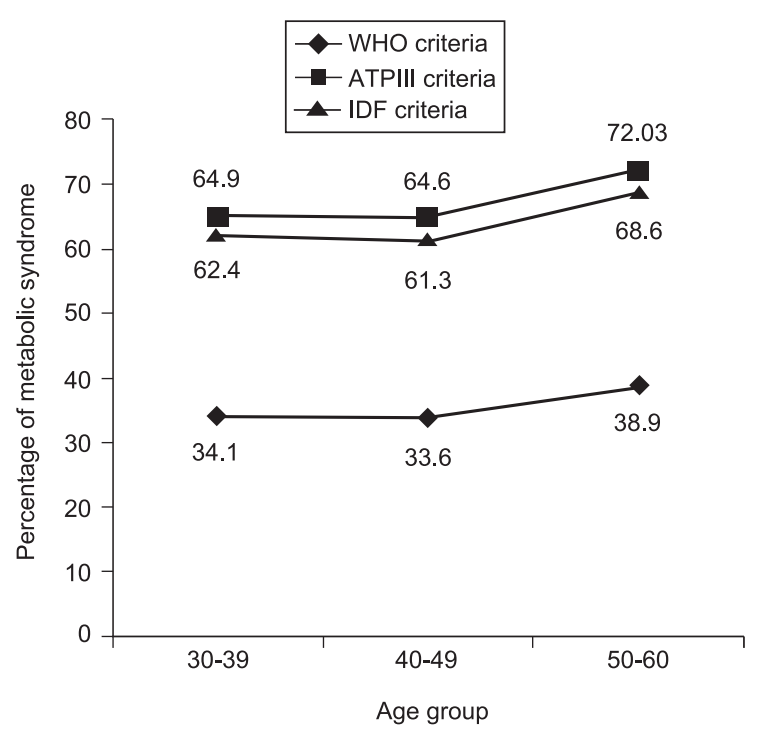

Fig.-1: Percentage of metabolic syndrome by different age group in different criteria, urban Dhaka, Bangladesh 2012. 
Distribution of anthropometric, clinical and biochemical parameters of the subjects with and without MS (according to Modified NCEP ATP III, WHO and IDF criteria)

Anthropometric profiles and results of medical examinations of the subjects by sex and 10-years age groups are shown in (TableIII) where characteristics of the respondent were describe. In Modified NCEP ATP III independent sample t-test mean of BMI, waist circumference, systolic Blood pressure, diastolic blood pressure, fasting blood glucose, high density lipoprotein \& triglyceride were present statistically significant difference between without MS and with MS $(\mathrm{P}<0.05)$ except Waist-hip ratio (See Table-IV) and according to WHO criteria BMI, waist circumference, Fasting blood glucose were statistically significant difference between without MS and with MS. Similarly fasting blood glucose \& triglyceride were statistically significant difference between without MS and with MS $(\mathrm{P}<0.05)$ according to IDF criteria. The percentage increased with age for both sexes using all three criteria in our hospital but more evident for women subjects.

\section{Table-III}

Means (Standard deviations) of anthropometric profiles and results of medical examinations by sex and 10 year age group in a hospital

\begin{tabular}{|c|c|c|c|c|c|c|c|c|}
\hline \multirow{3}{*}{$\begin{array}{l}\text { Indicators } \\
\text { Age group }\end{array}$} & \multicolumn{4}{|c|}{ Men $(\mathrm{N}=100)$} & \multicolumn{4}{|c|}{ Women $(\mathrm{N}=129)$} \\
\hline & $30-39$ & $40-49$ & $50-60$ & Total & $30-39$ & $40-49$ & $50-60$ & Total \\
\hline & $\mathrm{n}=23$ & $\mathrm{n}=46$ & $\mathrm{n}=31$ & $\mathrm{~N}=100$ & $\mathrm{n}=44$ & $\mathrm{n}=58$ & $\mathrm{n}=27$ & $\mathrm{~N}=129$ \\
\hline Height (cm) & $164.1(6.7)$ & $166.8(6.7)$ & $164.3(6.8)$ & $165(6.73)$ & $154.4(5.2)$ & $154.3(6.1)$ & $153.1 \quad(6.7)$ & $153.9(6)$ \\
\hline Weight (kg) & $68.3(13.5)$ & $69(8.8)$ & $66.1(10.2)$ & $67.8(10.83)$ & $61.2 \quad(10.8)$ & $59.5(8.6)$ & $63.4(12.8)$ & $61.4(10.7)$ \\
\hline BMI $\left(\mathrm{kg} / \mathrm{m}^{2}\right)$ & $25.2(3.6)$ & $24.8(2.4)$ & $24.4(3.0)$ & $24.8(3)$ & $25.6(3.9)$ & $25(3.6)$ & $26.9(4.1)$ & $25.8(3.9)$ \\
\hline $\mathrm{WC}^{\dagger}(\mathrm{cm})$ & $90.7(8.5)$ & $89.1(8.9)$ & $89.5(7.4)$ & $89.8(8.26)$ & $87.8(9.4)$ & $89(10.1)$ & $91.7(11.4)$ & $89.5(10.3)$ \\
\hline Triglycerides (mg/dl) & $200.4(60.6)$ & $165.4(54.2)$ & $162.3(46.2)$ & $176(53.57)$ & $162.3(71.7)$ & $171.866 .1)$ & $166.8(68.4)$ & $166.9(24.6)$ \\
\hline HDL-C $\mathrm{C}^{\dagger}(\mathrm{mg} / \mathrm{dl})$ & $36.6(5.7)$ & $35.9(5.2)$ & $36.3(4.8)$ & $36.3(5.23)$ & $36.9(7.1)$ & $36.6(6.2)$ & $38(6.9)$ & $37.2(6.7)$ \\
\hline $\mathrm{PG}^{\dagger}(\mathrm{mg} / \mathrm{dl})$ & $105.1(19.7)$ & $104(23.2)$ & $113.1(35.3)$ & $107.4(26.06)$ & $109.1(25.2)$ & $113.930 .2)$ & $109.4(23.5)$ & $110.8(6.16)$ \\
\hline Systolic BP (mmHg) & $125(17.5)$ & $122(15.5)$ & $124(15.6)$ & $123(16.2)$ & $113(14.3)$ & $115(17)$ & $134(13.5)$ & $121(14.9)$ \\
\hline Diastolic BP (mmHg) & $88 \quad(12.7)$ & $85 \quad(10.7)$ & $84(11.5)$ & $85(11.63)$ & $81(10.2)$ & $80(10)$ & $87(8.8)$ & $83(9.6)$ \\
\hline
\end{tabular}

${ }^{\dagger}$ WC=Waist circumference, HDL-C=HDL-Cholesterol, PG=Plasma glucose and *Significant at $<0.005$.

\section{Table-IV}

Distribution of anthropometric, clinical and biochemical parameters of the subjects with and without MS (according to Modified NCEP ATP III, WHO and IDF criteria)

in urban Bangladesh, 2012

\begin{tabular}{|c|c|c|c|c|c|c|c|c|c|}
\hline \multirow[t]{2}{*}{ Indicators } & \multicolumn{3}{|c|}{ Modified NCEP ATP III } & \multicolumn{3}{|c|}{ WHO } & \multicolumn{3}{|c|}{ IDF } \\
\hline & $\begin{array}{c}\text { With MS } \\
\mathrm{n}=64\end{array}$ & $\begin{array}{c}\text { Without MS } \\
n=165\end{array}$ & P-Value & $\begin{array}{c}\text { With MS } \\
\mathrm{n}=72\end{array}$ & $\begin{array}{c}\text { Without MS } \\
\mathrm{n}=157\end{array}$ & P-Value & $\begin{array}{c}\text { With MS } \\
n=140\end{array}$ & $\begin{array}{c}\text { Without MS } \\
n=89\end{array}$ & P-Value \\
\hline BMI & $23.4(2.7)$ & $26(3.5)$ & $0.001^{*}$ & $23.1(2.5)$ & $26.3(3.3)$ & $0.001^{*}$ & $24.1(3.1)$ & 25.9(3.9) & $0.040^{*}$ \\
\hline †WC (cm) & $82.7(10.1)$ & $92(7.7)$ & $0.001^{*}$ & $80.5(8.5)$ & $93.4(6.7)$ & $0.001^{*}$ & $88.5(9.7)$ & $91.0(8.8)$ & 0.085 \\
\hline Waist-hip ratio & $0.91(0.06)$ & $0.92(0.06)$ & 0.479 & $0.91(0.06)$ & $0.92(0.06)$ & 0.479 & $0.92(0.06)$ & $0.92(0.05)$ & 0.975 \\
\hline SBP & 113(13) & $12 \quad(17)$ & $0.001^{*}$ & $120(17)$ & $120(16)$ & 0.988 & $119(17)$ & 121( 16) & 0.440 \\
\hline DBP & $78(8)$ & $85(11)$ & $0.001^{*}$ & $82(11)$ & $84(11)$ & 0.456 & $83(10)$ & $84(11)$ & 0.281 \\
\hline FBG & $95(14)$ & 115(29) & $0.001^{*}$ & 104(28) & $112(26)$ & $0.050^{*}$ & $94(11)$ & $135(26)$ & $0.001^{*}$ \\
\hline HDL & $38(7)$ & $36(6)$ & $0.027^{*}$ & $37(6)$ & $36(6)$ & 0.130 & $37(6)$ & $36(6)$ & 0.183 \\
\hline Triglyceride & $132(45)$ & $184(62)$ & $0.001^{*}$ & $158(63)$ & $175(62)$ & 0.077 & $158(53)$ & 187( 71) & $0.001^{*}$ \\
\hline
\end{tabular}

†WC=Waist circumference, $\mathrm{FBG}=$ Fasting blood glucose

Independent sample t- test was performed to compare the difference between groups, * $p<0.05$ was taken as level of significance. 
Agreements between three criteria's (according to Modified NCEP ATP III, WHO and IDF criteria):

The participants who were classified as having metabolic syndrome by WHO criteria, all of them also met the criteria of ATP III. However $15 \%$ of the subjects identified as positive following the ATP III classification were not found to have condition according to WHO criteria, Good agreement was observed between ATPIII and WHO criteria $(\mathrm{k}=0.56)($ See table-V).In those subjects were observed between IDF and ATP III criterions for MS. Of the total participants having metabolic syndrome by IDF criteria, 94\% (84 out of 89) met the criteria of ATP III. IN contrast, the subjects without the metabolic syndrome according to the ATP III were positive following the IDF criteria $(\mathrm{k}=0.31)$ and the agreement was average. In those subject who were classified as having the metabolic syndrome according to IDF criteria $43.3 \%$ satisfied the WHO criteria. Conversely the participants without the syndrome according to the IDF criteria $76.4 \%$ met the criteria of WHO. The agreement between WHO and IDF is slight $(\mathrm{k}=0.11)$ but higher than the observed agreement between ATPIII \& IDF.ATP III and WHO criteria showed good agreement $(\mathrm{k}=0.56)$ compared to ATP III with IDF $(\mathrm{k}=0.31)$ and WHO with IDF $(\mathrm{k}=0.11)$ criteria respectively.

\section{Table V}

Agreements among the modified NCEP ATPIII, IDF and WHO criteria in diagnosing metabolic syndrome applying urban Bangladesh, 2012

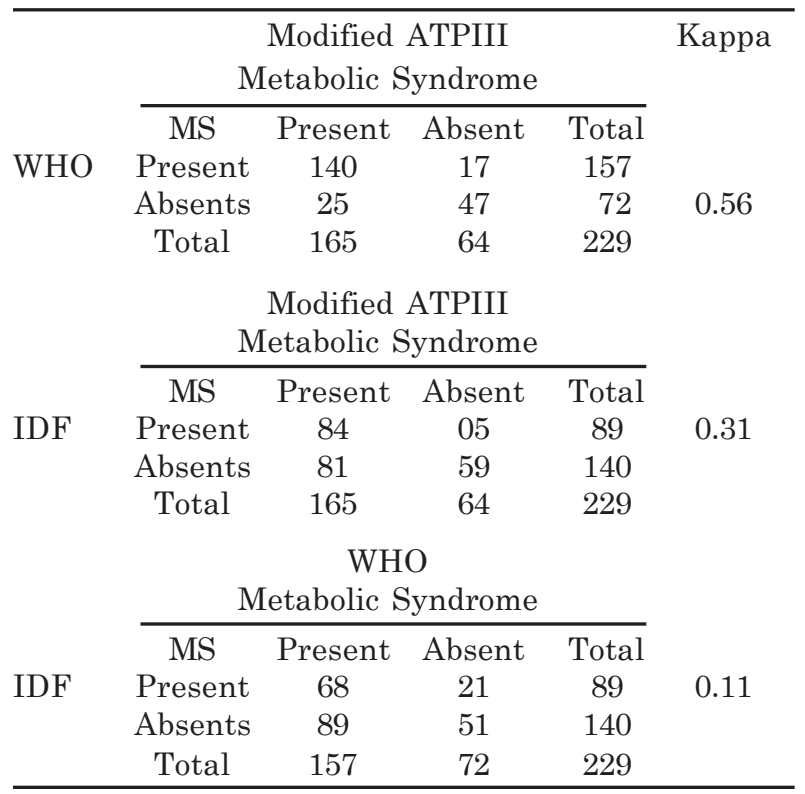

\section{Discussion:}

Prevalence of metabolic syndrome varies with age and sex. This paper showed the diverse percentage of the metabolic syndrome ranging from $39 \%, 69 \%$ and $72 \%$ under WHO, IDF and ATP III using three different definitions. In a recent study, ${ }^{9}$ the prevalence of MS in Chinese was $50 \%, 55 \%$ and $70 \%$ under the IDF, ATPIII and WHO definitions respectively. This is similar to Indians, South Asians, and US population. ${ }^{10,11}$

The possible foremost reason for higher prevalence rates of metabolic syndrome following ATP III appeared to be its inclusion of flexible waist/hip ratio for the Asian subjects and use of new cut-off for fasting blood glucose threshold. The IDF and ATP III definitions use the same five components and their defined cut- off values were also identical other than "central obesity" which was required as a core component in the IDF classification. In contrast, the ATP III definition requires central obesity as one of the five equally weighted components for the required definition. ${ }^{12,13}$

Higher prevalence of the metabolic syndrome in women compared to men using all three criteria in this study was consistent with other findings. ${ }^{9-14}$ Sex differences of the prevalence of metabolic syndrome were evident in different ethnic population. The significant higher prevalence of MS in Bangladeshi women was likely to had been influenced by high prevalence of low HDL cholesterol and higher rates of central obesity, measured by WHR or WC compared to men. High prevalence of low HDL- cholesterol and obesity were also reported among Indian women and others south Asian Women. ${ }^{10-12}$ This may indicate similar lifestyle factors such as food habits and less physical activity among the women of Indian subcontinent including Bangladesh. ${ }^{13-15}$

The importance of metabolic syndrome as a clinical entity is often discussed in recent scientific communications, but characterization of the syndrome has relevance in identifying individuals at risk both for DM and CVD. Owing to the different classification proposed by the WHO, ATP III and IDF may considerably influence the estimation resulting in diverse prevalence in different population. The significance of MS should therefore be appraised in relation to its appropriateness for the identification of the individuals at risk. 
Our results suggest a higher proportion of MS due to hospital study, was observed following ATP III compare to IDF and the WHO criteria.

ATP III and WHO criteria showed good agreement $(\mathrm{k}=0.56)$ compared to ATP III with IDF $(\mathrm{k}=0.31)$ and WHO with IDF $(\mathrm{k}=0.11)$ criteria. Our data was an agreement with that of Indian study which also found XX. ${ }^{10}$ The foremost rationale explanation for the higher rate of MS following ATP III seems to be predominant focus on the modified waist circumference for the Asian participants. However, MS presence following WHO criteria in those with impaired glucose regulation is comparable with ATP III definition. Our results should to be examined in a follow-up study among the high-risk individuals in order to estimate its proven significance. This may help to take appropriate measure to prevent and or delay the onset of $\mathrm{DM}$ and or CVD.

\section{Limitation:}

The major limitation of the study was that the subjects were a health cheek-up population and selection biases may occur in such a setting. Health check- up participants generally more concern about their health than non participants. May be the percentage of risk factor of MS were high in this circumstance. It was a hospital based study. So, high risk subjects were present in large percentage. A longitudinal study should be conducted to determine the relationship with risk factor of MS with different criteria.

\section{Conclusion:}

Metabolic syndrome appeared to be highly prevalent in Bangladesh. Highest prevalence was observed following ATP III definition may be predominant focus on the modified waist circumference for Asian subjects. However, MS prevalence following WHO criteria in those with impaired glucose regulation is comparable with ATP III definition. Follow up study needed to examine the significance of MS following all definitions for the assessment of risk for diabetes and or cardiovascular disease.

\section{Acknowledgements}

We acknowledge the contribution of our team members for their continuous effort in the collection of data. We express our appreciation to the authority of National Centre for control of Rheumatic Fever \& Heart disease. We are grateful to all participants in the study for their active co-operation.

\section{References:}

1. Alberti KG, Zimmet P, Shaw J. Metabolic syndrome: a new world-wide definition. A Consensus Statement from the nternational Diabetes Federation. Diabet Med 2006; 23: 469-480.

2. Eckel RH, Grundy SM, Zimmet PZ. The metabolic syndrome.Lancet 2005; 365: 1415-1428.

3. Cameron AJ, Shaw JE, Zimmet PZ. The metabolic syndrome: Prevalence in worldwide populations. Endocrinol Metab Clin North Am 2004;33:351-375.

4. National Cholesterol Education Program (NCEP) Expert Panel on Detection, Evaluation and Treatment of High Blood Cholesterol in Adults (Adult treatment panel III) 2002, "Third report of the National Cholesterol Education Program (NCEP) Expert Panel on Detection, Evaluation and Treatment of High Blood Cholesterol in adults (Adult treatment panel III) final report," Circulation 2002; 106: 31433421.

5. Eckel RH, Grundy SM, Zimmet PZ. The Metaboloc syndrome. Lancet 2005;365:1415-1428.

6. Abdul M, Mahboob A, Shahabuddin M et al. Metabolic Syndrome- a Review. Bangladesh Heart Journal; 22(1): 36-44.

7. WHO expert consultation. Appropriate body-mass index for asian populations and its implications for policy and intervention strategies. Lancet 2004; 363: 157-163.

8. International Diabetes Federation, The IDF consensus worldwide definition of the metabolic syndrome, Retrived June 10, 2005, from http:// www.idf.org/webdata/docs/ Metac syndrome def.pdf.

9. Lu B, Yang Y, Song X et al. An evaluation of the International Diabetes Federation definition of metabolic syndrome in Chinese patients older than 30 years and diagnosed with type 2 diabetes mellitus. Metabol Clin Exper 2006; 55:1088-1096.

10. Rama chandran A, snehalatha C, et al. Metabolic syndrome in urban Asian Indian adults-a population studies using modified ATP III criteria. Diabetes Res Clin Pract 2003;60:199-204.

11. Rajeev G, Prakash C, Deedwania A et al. Prevalence of metabolic syndrome in an Indian urban population. Int $J$ Cardiol 2004;97:257-261.

12. Ko GTC, Cockram Cs, et al. High prevalence of metabolic syndrome in Hong Kong Chinese- comparison of three diagnostic criteria. Diabetes Res Clin Pract 2005;69:160-168.

13. Earl SF, Wayne HG Ali HM et al. Increasing prevalence of the metabolic syndrome among U.S adults. Diabetes Care 2004; 27:2444-2449.

14. Ford ES, Giles WH. A comparison of prevalence of the metabolic syndrome using two proposed definitions. Diabetes Care 2003; 26:575-581.

15. Earl SF. Prevalence of metabolic syndrome defined by IDF among adults in the U.S. Diabetes Care 2005; 28:2745-2749.

16. Ang LW, Ma S, et al The metabolic syndrome in Chinese, Malays and Asian Indians, factor analysis of data from 1998 Singapore National Health Survey. Diabetes Res Clin Pract 2005; 67:53-62. 